\title{
ChemComm
}

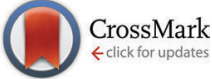

Cite this: Chem. Commun., 2016, 52,6237

Received 3rd March 2016, Accepted 4th April 2016

DOI: $10.1039 / c 6 c c 01915 c$

www.rsc.org/chemcomm

\section{Nickel(0)-catalyzed intramolecular reductive coupling of alkenes and aldehydes or ketones with hydrosilanes $\dagger$}

\author{
Yukari Hayashi, ${ }^{a}$ Yoichi Hoshimoto, ${ }^{a b}$ Ravindra Kumar, ${ }^{a}$ Masato Ohashi ${ }^{a}$ and \\ Sensuke Ogoshi*a
}

A nickel(0)-catalyzed reductive coupling of aldehydes and simple alkenes with hydrosilanes has been developed. A variety of silylprotected 1-indanol derivatives were prepared in a highly diastereoselective manner (up to $>99: 1 \mathrm{dr}$ ) by employing a combination of nickel(0)/N-heterocyclic carbene and triethylsilane. The present system was also applied to a reductive coupling with ketones. Preliminary results of a nickel( 0$)$-catalyzed asymmetric three-component coupling reaction of an aldehyde, an alkene, and triethylsilane are also shown.

A high level of efficiency and wide applicability would make the oxidative cyclization of two $\pi$ components with nickel(0) a key process in a variety of catalytic molecular transformations proceeding through carbon-carbon bond formation. Indeed, much progress has been made in nickel(0)-catalyzed molecular transformations, which were proposed to take place through hetero-nickelacycle intermediates generated by oxidative cyclization. ${ }^{1,2}$ We have also contributed to these developments ${ }^{1 a, b}$ by the direct observation of the formation of oxanickelacycles from $\left(\eta^{2}\right.$-aldehyde: $\eta^{2}$-alkene)nickel complexes through oxidative cyclization, ${ }^{3 a}$ and by the expansion of this stoichiometric process to a catalytic hydroacylation yielding five- and six-membered benzocyclic ketones (Scheme 1a). ${ }^{3 b}$ This hydroacylation was proposed to proceed through $\beta$-hydride elimination from the oxanickelacycle intermediate, which was supported by the results of stoichiometric experiments. Oxanickelacycles could efficiently react with a reductant such as silanes, organoboranes, and organozincs, and these have been the key for many nickel(0)-catalyzed reductive coupling reactions. ${ }^{2}$ Among them, the reactions of alkynes and aldehydes have been well-developed. ${ }^{4,5}$ The use of 1,3 -dienes $^{6}$ or allenes ${ }^{7}$ instead of alkynes was also reported. Nevertheless, the use of alkenes has been rare, which is probably due to the difficulty of

\footnotetext{
${ }^{a}$ Department of Applied Chemistry, Faculty of Engineering, Osaka University, Suita, Osaka 565-0871, Japan. E-mail: ogoshi@chem.eng.osaka-u.ac.jp

${ }^{b}$ Frontier Research Base for Global Young Researchers, Graduate School of Engineering, Osaka University, Suita, Osaka 565-0871, Japan

$\dagger$ Electronic supplementary information (ESI) available: Experimental procedures and characterization data. See DOI: 10.1039/c6cc01915c
}

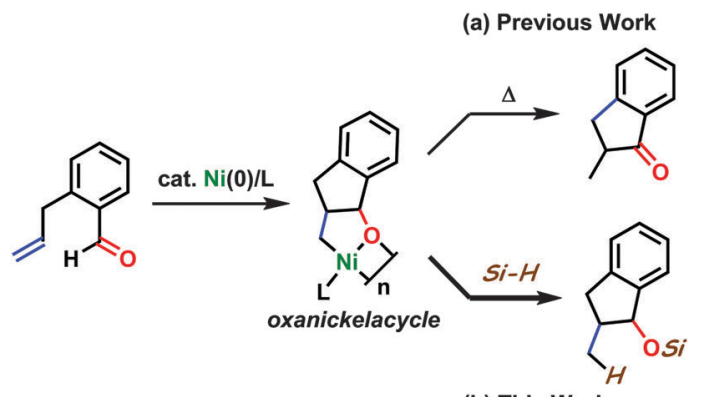

(b) This Work

Scheme 1 Catalytic transformations of $O$-allylbenzaldehyde through the oxanickelacycle intermediate.

both the simultaneous coordination of these two components to nickel $(0)$ and the subsequent oxidative cyclization. ${ }^{2 e}$ Thus far, the use of alkenes has been limited to the highly reactive ones such as methylenecyclopropane, ${ }^{8}$ norbornene ${ }^{9}$ and tetrafluoroethylene.$^{10}$ Herein, we report an intramolecular reductive coupling reaction of simple alkenes and aldehydes with hydrosilanes catalyzed by nickel(0)/N-heterocyclic carbene (NHC), yielding a variety of silyl-protected 1-indanol derivatives in a diastereoselective manner (Scheme 1b). We also demonstrate the corresponding reductive coupling reaction with ketones instead of aldehydes. ${ }^{11}$

The reaction conditions were optimized through the use of $o$-allylbenzaldehyde (1a) and triethylsilane (Table 1). The formation of 1-triethylsiloxy-2-methylindan (2a) was confirmed when NHC ligands were employed, whereas $\mathrm{PPh}_{3}$ and $\mathrm{PCy}_{3}$ were not effective (entries 1-6). Among the NHCs we examined, SIPr gave 2a in a better yield at room temperature $(69 \%$, entry 5$)$. In this reaction system, $\left(\eta^{6}\right.$-toluene) Ni(SIPr) (TNSI) was generated as a precursor for an active nickel(0)/SIPr catalyst. ${ }^{12}$ Indeed, the reaction conducted with TNSI provided 2a without a loss of the yield compared with the system comprising $\mathrm{Ni}(\operatorname{cod})_{2}$ and SIPr (entry 7 vs. 5). We thus used TNSI for the further optimization since TNSI can be prepared using a single-step, one-pot, and gram-scale method, ${ }^{12}$ and it readily dissolves in a 
Table 1 Optimization of reaction conditions
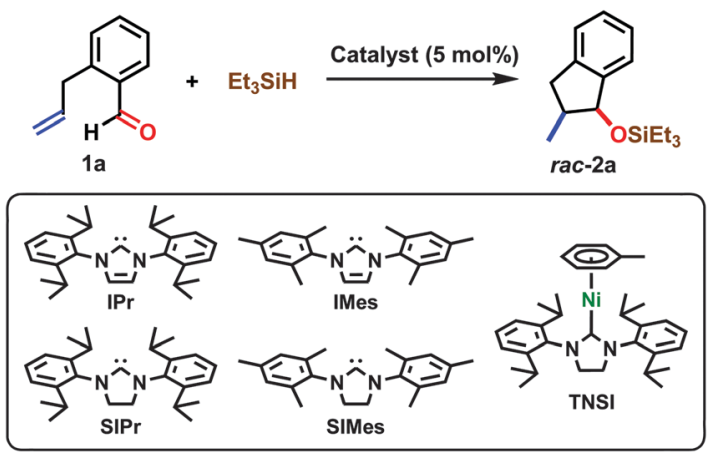

\begin{tabular}{|c|c|c|c|c|c|c|}
\hline Entry & Catalyst & Solvent & $\begin{array}{l}\text { Temp. } \\
\left({ }^{\circ} \mathrm{C}\right)\end{array}$ & $\begin{array}{l}\text { Time } \\
\text { (h) }\end{array}$ & $\begin{array}{l}\text { Yield }^{b} \\
(\%)\end{array}$ & $\mathrm{dr}^{b}$ \\
\hline $1^{a}$ & $\mathrm{Ni}(\operatorname{cod})_{2} / \mathrm{PCy}_{3}$ & Toluene & $\mathrm{rt}$ & 24 & $<1$ & - \\
\hline $2^{a}$ & $\mathrm{Ni}(\operatorname{cod})_{2} / \mathrm{PPh}_{3}$ & Toluene & $\mathrm{rt}$ & 24 & $<1$ & - \\
\hline 3 & $\mathrm{Ni}(\operatorname{cod})_{2} / \mathrm{IPr}$ & Toluene & $\mathrm{rt}$ & 24 & 14 & $86: 14$ \\
\hline 4 & $\mathrm{Ni}(\operatorname{cod})_{2} / \mathrm{IMes}$ & Toluene & $\mathrm{rt}$ & 24 & 5 & $70: 30$ \\
\hline 5 & $\mathrm{Ni}(\operatorname{cod})_{2} / \mathrm{SIPr}$ & Toluene & $\mathrm{rt}$ & 24 & 69 & $94: 6$ \\
\hline 6 & $\mathrm{Ni}(\operatorname{cod})_{2} /$ SIMes & Toluene & $\mathrm{rt}$ & 24 & 20 & $69: 31$ \\
\hline 7 & TNSI & Toluene & $\mathrm{rt}$ & 24 & 69 & $93: 7$ \\
\hline 8 & TNSI & Toluene & 40 & 12 & $94(99)^{c}$ & $>99: 1$ \\
\hline 9 & TNSI & $\mathrm{THF}$ & 40 & 12 & 83 & $>99: 1$ \\
\hline 10 & TNSI & 1,4-Dioxane & 40 & 12 & 92 & $>99: 1$ \\
\hline 11 & TNSI & Cyclohexane & 40 & 12 & 80 & $92: 8$ \\
\hline
\end{tabular}

${ }^{a}$ Employment of $5 \mathrm{~mol} \%$ of $\mathrm{Ni}(\operatorname{cod})_{2}$ and $10 \mathrm{~mol} \%$ of phosphine ligands. ${ }^{b}$ Determined by GC using $n$-pentadecane as an internal standard. ${ }^{c}$ Isolated yield.

variety of solvents including alkane media, unlike $\mathrm{Ni}(\operatorname{cod})_{2}$. In addition, the experimental manipulations were simplified and made more accurate by using the prepared nickel( 0 ) complex. The reaction at $40{ }^{\circ} \mathrm{C}$ resulted in improvements in both yield and diastereoselectivity giving 2a in 99\% isolated yield (entry 8). Among the various solvents we examined, toluene gave the highest yield and diastereoselectivity (entries 8-11). The syn-conformation between the silyl ether and the methyl groups in $\mathbf{2 a}$ was confirmed by comparison with reports in the literature after desilylation using TBAF ( $94 \%$ isolated yield). ${ }^{13,14}$

The impact of the steric and electronic nature of silanes on both the yield and diastereoselectivity was not significant (Table 2). Good to excellent yields and diastereoselectivities were obtained across a broad range of silanes, with the exception of (EtO) ${ }_{3} \mathrm{SiH}$ (entry 7). Other reducing reagents such as diethylzinc or triethylborane were less effective in this reaction. ${ }^{14}$

The scope of the reaction was investigated with respect to $o$-allylbenzaldehyde derivatives (1a-j) (Table 3). When electrondonating groups were bonded to the benzene ring $(\mathbf{1 b}-\mathbf{c})$, the reaction proceeded well to give the corresponding silylprotected 1-indanol derivatives in $>97 \%$ isolated yields. The fluorine substituted products (2d-f) were obtained in $>89 \%$ isolated yields; however, a trace amount of chlorine-substituted product $2 \mathrm{~g}$ was obtained. Both products with the $o$-benzyl group (2h) and the naphthyl structure (2i) were obtained in $>99 \%$ isolated yields. In all of these reactions, the syn-isomer was obtained with $>99: 1 \mathrm{dr}$. The substituted allyl group was also employed to afford $2 \mathbf{j}$ in $>99 \%$ isolated yield.
Table 2 Scope of hydrosilanes

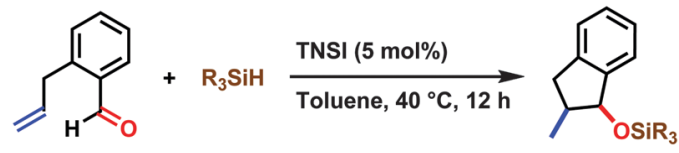

$1 \mathrm{a}$

\begin{tabular}{lllr}
\hline Entry & $\mathrm{R}_{3} \mathrm{SiH}$ & Yield $^{a}(\%)$ & $\mathrm{dr}^{a}$ \\
\hline 1 & $\mathrm{Et}_{3} \mathrm{SiH}$ & $94(99)^{b}$ & $>99: 1$ \\
2 & $\left.{ }^{(}{ }^{\mathrm{Pr}}\right)_{3} \mathrm{SiH}$ & 98 & $96: 4$ \\
3 & ${ }^{t} \mathrm{BuMe}{ }_{2} \mathrm{SiH}$ & 86 & $>99: 1$ \\
4 & $\mathrm{PhMe}_{2} \mathrm{SiH}$ & 90 & $96: 4$ \\
5 & $\mathrm{Ph}_{2} \mathrm{MeSiH}$ & 86 & $>99: 1$ \\
6 & $\mathrm{Ph}_{3} \mathrm{SiH}$ & 98 & $>99: 1$ \\
7 & $(\mathrm{EtO})_{3} \mathrm{SiH}$ & 49 & $96: 4$
\end{tabular}

${ }^{a}$ Determined by GC using $n$-pentadecane as an internal standard. ${ }^{b}$ Isolated yield.

Table 3 Reductive coupling of alkenes and aldehydes with triethylsilane ${ }^{a}$

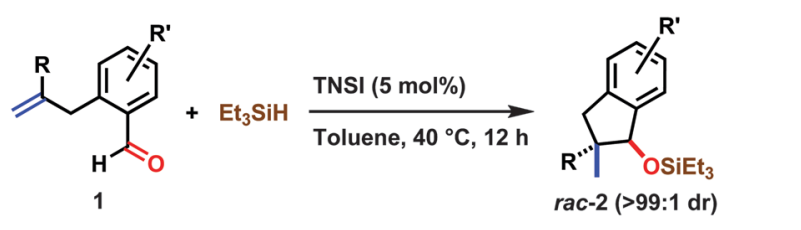

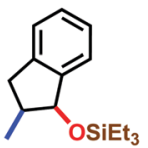

$2 a$ $99 \%$<smiles>CCOC1c2cc(C(F)(F)F)ccc2CC1C</smiles>

$2 f$ $>99 \%$

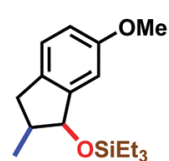

2b

$97 \%$

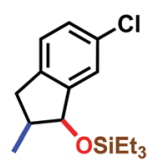

$2 \mathrm{~g}$
$<5 \%{ }^{b}$

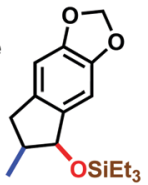

2c

$>99 \%$

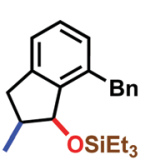

2h $>99 \%$

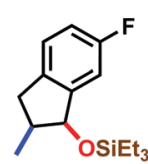

2d

$90 \%$

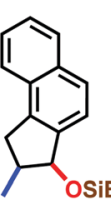

$2 i$
$>99 \%$
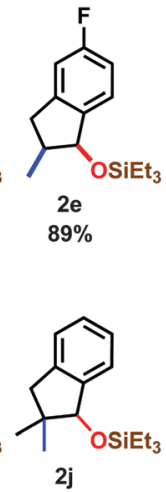

$>99 \%$
${ }^{a}$ The isolated yields of $\mathbf{2}$ are presented. Diastereoselectivity was determined by GC. ${ }^{b}$ Determined by GC using $n$-pentadecane as an internal standard.
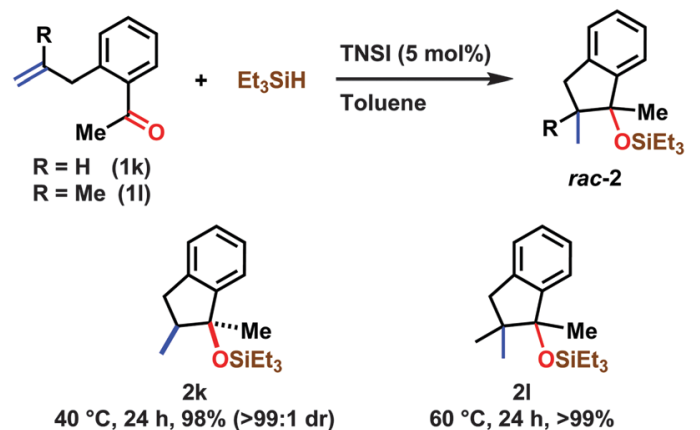

Scheme 2 Reductive coupling of ketones and alkenes with triethylsilane.

The results of a reductive coupling of alkenes and ketones with triethylsilane are shown in Scheme 2. The reaction of $o$-allylacetophenone $(\mathbf{1 k})$ took place efficiently to afford the 


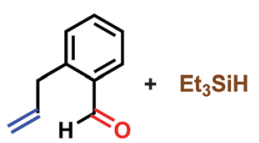

$1 \mathrm{a}$

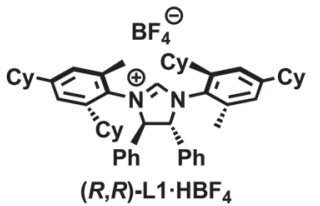

$92 \%$

$>99: 1 \mathrm{dr}, 15 \%$ ee

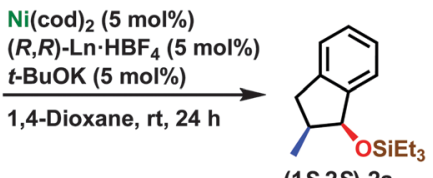

$(1 S, 2 S)-2 a$

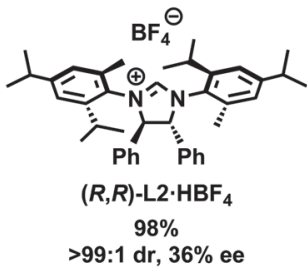

Scheme 3 Enantioselective reductive coupling of 1a with triethylsilane.

corresponding silyl-protected 1-methyl-1-indanol (2k) in 98\% isolated yield and $>99: 1 \mathrm{dr}$. The syn-conformation between the silyl ether and the methyl groups in $2 \mathbf{k}$ was confirmed by comparison with reports in the literature after desilylation using TBAF. ${ }^{14,15}$ The substituted allyl group was also employed at $60{ }^{\circ} \mathrm{C}$, giving $2 \mathbf{l}$ in $>99 \%$ isolated yield.

Preliminary results of the expansion of the presented reaction to an enantioselective version are given in Scheme $3 .{ }^{14}$ Chiral NHC ligands generated in situ by treating the imidazolinium salts $\left(\mathrm{Ln} \cdot \mathrm{HBF}_{4}\right)$ with $t$-BuOK were applied in this reaction. The reductive coupling of $\mathbf{1 a}$ with triethylsilane was catalyzed by $5 \mathrm{~mol} \%$ of $\mathrm{Ni}(\operatorname{cod})_{2}$ and $\mathbf{L 1}$ at room temperature for $24 \mathrm{~h}$ in 1,4-dioxane and provided $2 \mathrm{a}$ in $92 \%$ isolated yield, $>99: 1 \mathrm{dr}$, and $15 \%$ ee. The enantiomeric excess of 2 a was determined using supercritical fluid chromatography (SFC) after converting it into 2-methyl-1-indanol (3a) through desilylation using TBAF. $^{14}$ A novel ligand $\mathbf{L} 2$ was prepared according to the procedures of $\mathbf{L} 1$ reported by Montgomery et al. ${ }^{16}$ and the system utilizing $\mathbf{L} 2$ afforded further improved results (98\% isolated yield, $>99: 1 \mathrm{dr}$, and $38 \%$ ee). The absolute configuration of $(1 S, 2 S)-2 \mathrm{a}$ was confirmed by comparing the specific rotation of the corresponding desilylation product $(1 S, 2 S)$-3a with data found in the literature. $^{13 b}$

This intramolecular reductive coupling might proceed through oxidative cyclization of an aldehyde and an alkene affording an oxanickelacycle intermediate as shown in Scheme $1 .{ }^{17}$ The oxidative cyclization process would be promoted by a Lewis acidic silane reagent. ${ }^{2 e, 3 a}$ The subsequent $\sigma$-bond metathesis and reductive elimination might give the product. Analogous mechanisms proceeding through oxanickelacycle intermediates were proposed in the reductive coupling reaction of aldehydes and alkynes. ${ }^{18}$

In conclusion, the nickel(0)/NHC-catalyzed diastereoselective intramolecular reductive coupling of alkenes and aldehydes with hydrosilanes was demonstrated. A variety of silyl-protected 1-indanol derivatives were prepared in excellent yields with perfect diastereoselectivities. The corresponding reductive coupling with ketones was also achieved. The preliminary results on the enantioselective reductive coupling were shown, in which the target indanol was obtained with a perfect diastereoselectivity and a promising enantioselectivity. Further development of this enantioselective process is ongoing in our group.
This work was supported by Grants-in-Aid for Young Scientists (A) (25708018) and Grants-in-Aid for Scientific Research on Innovative Area "Precise Formation of a Catalyst Having a Specified Field for Use in Extremely Difficult Substrate Conversion Reactions" (15H05803) and "Stimuli-responsive Chemical Species” (15H00943) from MEXT and by ACT-C from JST. Y. H. acknowledges support from the Frontier Research Base for Global Young Researchers, Osaka University, on the Program of MEXT. Y. H. expresses her special thanks for the Research Fellowship for Young Scientists from JSPS.

\section{Notes and references}

1 For selected recent reviews and books on the nickel(0)-catalyzed reactions via nickelacycle intermediates, see: (a) M. Ohashi, Y. Hoshimoto and S. Ogoshi, Dalton Trans., 2015, 44, 12060; (b) Y. Hoshimoto, M. Ohashi and S. Ogoshi, Acc. Chem. Res., 2015, 48, 1746; (c) S. Z. Tasker, E. A. Standley and T. F. Jamison, Nature, 2014, 509, 299; (d) J. Montgomery, Organonickel Chemistry, in Organometallics in Synthesis: Fourth Manual, ed. B. H. Lipshutz, Wiley, Hoboken, NJ, 2013, pp. 319-428; (e) J. C. Leung and M. J. Krische, Chem. Sci., 2012, 3, 2202; $(f)$ Modern Organonickel Chemistry, ed. Y. Tamaru, Wiely-VCH, Weinheim, 2005.

2 For selected recent reviews on nickel(0)-catalyzed reductive coupling reactions, see: (a) E. A. Standley, S. Z. Tasker, K. L. Jensen and T. F. Jamison, Acc. Chem. Res., 2015, 48, 1503; (b) E. P. Jackson, H. A. Malik, G. J. Sormunen, R. D. Baxter, P. Liu, H. Wang, A.-R. Shareef and J. Montgomery, Acc. Chem. Res., 2015, 48, 1736; (c) K. Tanaka and Y. Tajima, Eur. J. Org. Chem., 2012, 3715; (d) M. Jeganmohan and C.-H. Cheng, Chem. - Eur. J., 2008, 14, 10876; (e) S.-S. Ng, C.-Y. Ho, K. D. Schleicher and T. F. Jamison, Pure Appl. Chem., 2008, 80, 929; $(f)$ R. M. Moslin, K. Miller-Moslin and T. F. Jamison, Chem. Commun., 2007, 4441; $(g)$ J. Montgomery, Angew. Chem., Int. Ed., 2004, 43, 3890; (h) S.-i. Ikeda, Angew. Chem., Int. Ed., 2003, 42, 5120; (i) J. Montgomery, Acc. Chem. Res., 2000, $33,467$.

3 (a) S. Ogoshi, M.-a. Oka and H. Kurosawa, J. Am. Chem. Soc., 2004, 126, 11802; $(b)$ Y. Hoshimoto, Y. Hayashi, H. Suzuki, M. Ohashi and S. Ogoshi, Angew. Chem., Int. Ed., 2012, 51, 10812.

4 (a) C.-Y. Zhou, S.-F. Zhu, L.-X. Wang and Q.-L. Zhou, J. Am. Chem. Soc., 2010, 132, 10955; (b) K. M. Miller, W.-S. Huang and T. F. Jamison, J. Am. Chem. Soc., 2003, 125, 3442; (c) W.-S. Huang, J. Chan and T. F. Jamison, Org. Lett., 2000, 2, 4221; (d) X.-Q. Tang and J. Montgomery, J. Am. Chem. Soc., 2000, 122, 6950; (e) X.-Q. Tang and J. Montgomery, J. Am. Chem. Soc., 1999, 121, 6098; $(f)$ E. Oblinger and J. Montgomery, J. Am. Chem. Soc., 1997, 119, 9065.

5 Nickel(0)-catalyzed reductive coupling of 1,6-enynes and aldehydes, see: R. M. Moslin, K. M. Miller and T. F. Jamison, Tetrahedron, 2006, 62, 7598 and references therein.

6 N. Saito, Y. Sugimura and Y. Sato, Org. Lett., 2010, 12, 3494 and references therein.

7 (a) S.-S. Ng and T. F. Jamison, J. Am. Chem. Soc., 2005, 127, 7320; (b) S.-K. Kang and S.-K. Yoon, Chem. Commun., 2002, 2634; (c) J. Montgomery and M. Song, Org. Lett., 2002, 4, 4009.

8 K. Ogata, Y. Atsuumi and S.-i. Fukuzawa, Org. Lett., 2010, 12, 4536.

9 (a) K. Ogata, A. Toh, D. Shimada and S.-i. Fukuzawa, Chem. Lett., 2012, 41, 157; (b) K. Ogata, Y. Atsuumi, D. Shimada and S.-i. Fukuzawa, Angew. Chem., Int. Ed., 2011, 50, 5896.

10 (a) M. Ohashi, T. Kawashima, T. Taniguchi, K. Kikushima and S. Ogoshi, Organometallics, 2015, 34, 1604; (b) M. Ohashi, H. Shirataki, K. Kikushima and S. Ogoshi, J. Am. Chem. Soc., 2015, 137, 6496.

11 Nickel(0)-catalyzed reductive coupling with ketones, see ref. 6 and: (a) W. Fu, M. Nie, A. Wang, Z. Cao and W. Tang, Angew. Chem., Int. Ed., 2015, 54, 2520; (b) K. M. Miller and T. F. Jamison, Org. Lett., 2005, 7, 3077; (c) J. Chan and T. F. Jamison, J. Am. Chem. Soc., 2004, 126, 10682.

12 Y. Hoshimoto, Y. Hayashi, H. Suzuki, M. Ohashi and S. Ogoshi, Organometallics, 2014, 33, 1276.

13 (a) P. A. Marshall and R. H. Prager, Aust. J. Chem., 1979, 32, 1251; (b) R. Fernández, A. Ros, A. Magriz, H. Dietrich and J. M. Lassaletta, Tetrahedron, 2007, 63, 6755. 
14 See the $\mathrm{ESI} \dagger$ for details.

15 N. M. Kablaoui and S. L. Buchwald, J. Am. Chem. Soc., 1996, 118, 3182.

16 M. R. Chaulagain, G. J. Sormunen and J. Montgomery, J. Am. Chem. Soc., 2007, 129, 9568.

17 A mechanism initiated by oxidative addition of hydrosilane to nickel(0) yielding a nickel(II) hydrido silyl complex is unlikely. Stoichiometric treatment of hydrosilane with TNSI was examined at room temperature and no observable change was confirmed by NMR spectroscopy.

18 (a) E. P. Jackson and J. Montgomery, J. Am. Chem. Soc., 2015, 137, 958; (b) M. T. Haynes II, P. Liu, R. D. Baxter, A. J. Nett, K. N. Houk and J. Montgomery, J. Am. Chem. Soc., 2014, 136, 17495; (c) P. Liu, P. McCarren, P. H.-Y. Cheong, T. F. Jamison and K. N. Houk, J. Am. Chem. Soc., 2010, 132, 2050; (d) N. Saito, T. Katayama and Y. Sato, Org. Lett., 2008, 10, 3829. 